\title{
A Made-in-Canada Second Language Framework for K-12 Education: Another Case Where No Prophet is Accepted in their Own Land
}

\author{
Monique Bournot-Trites \\ University of British Columbia \\ Lucas Friesen \\ University of British Columbia \\ Carl Ruest \\ University of British Columbia \\ Bruno D. Zumbo \\ University of British Columbia
}

\begin{abstract}
To ensure quality of education, a language framework should be the foundation on which second language curricula are developed. In 2010, the Council of Ministers of Education, Canada (CMEC), as suggested by Vandergrift (2006a, 2006b), recommended the use of the Common European Framework of Reference (CEFR) in the K-12 Canadian school context and presented several considerations for adaptation before it should be adopted and used. Although the CEFR is partially used across Canada, few of the CMEC's considerations have been met to date. Given this state of affairs, we suggest the made-in-Canada, Canadian Language Benchmarks and les Niveaux de compétence linguistique canadiens (CLB/NCLC) as an alternative. We argue that the CLB/NCLC, profoundly revised in 2012, best embrace the Canadian context and, using Vandergrift's criteria for a valid language framework, that CLB/NCLC are now superior to the CEFR in many aspects.
\end{abstract}

\section{Résumé}

Pour garantir une éducation de qualité, un cadre linguistique devrait être l'assise sur laquelle les programmes de langue seconde sont élaborés. En 2010, le Conseil des ministres de l'Éducation, Canada (CMEC), comme l'a suggéré Vandergrift (2006a, 2006b), a recommandé l'utilisation du Cadre européen commun de référence (CECR) dans le contexte scolaire canadien et a présenté plusieurs considérations pour son adaptation avant qu'il ne soit adopté et utilisé. Bien que le CECR soit partiellement utilisé au Canada, peu des considérations du CMEC ont été introduites à ce jour. Compte tenu de cet état de fait, nous suggérons l'alternative canadienne, les Canadian Language Benchmarks et les Niveaux de compétence linguistique canadiens (CLB/NCLC). Nous soutenons que les CLB/NCLC, profondément révisés en 2012, correspondent le mieux au contexte canadien et, en utilisant les critères de Vandergrift pour un cadre linguistique valide, que les CLB/NCLC sont maintenant, à bien des égards, supérieurs au CECR. 


\section{A Made-in-Canada Second Language Framework for K-12 Education: Another Case Where No Prophet is Accepted in their Own Land}

A language framework should be the foundation for the development of second language (L2) curricula which in turn enables students to become competent in the L2 they study. In Canada, no language framework is universally used for K-12 curriculum development. To remedy this gap, in 2006, Vandergrift (2006a, 2006b) assessed various language frameworks available for use in Canada and recommended that Canada adopt the Common European Framework of Reference (CEFR). In 2010, recognizing the importance of a language framework for curriculum development, the Council of Ministers of Education, Canada (CMEC) endorsed Vandergrift's proposition and recommended the use of the CEFR (Council of Europe (CoE), 2001) as a framework for L2 learning in Canadian schools. Developed by the CoE (2001), the CEFR was "intended to overcome the barriers to communication among professionals working in the field of modern languages arising from the different educational systems in Europe" (CoE, 2001 p. 7). In Canada, the CEFR could be used as "a tool to track learner progress and facilitate recognition of linguistic competencies across Canada and internationally" (Arnott et al., 2017, p. 32). The CMEC (2010) report recognizes that Canada needs to have common reference levels for teachers' report cards, for use as a Canadian standard for language proficiency, and for developing self-assessment portfolios for K-12 students. The CMEC (2010) also specified that the CEFR could not be implemented in Canadian schools without major adaptations, such as developing and validating sub-levels and considering intercultural competence in the Canadian context.

Unfortunately, to date, very little of this work has been done (Arnott et al., 2017). Moreover, in the light of major developments of the Canadian Language Benchmarks/Niveaux de compétence linguistique canadiens (CLB/NCLC) (Citizenship and Immigration Canada [CIC] \& Centre for Canadian Language Benchmarks [CCLB], 2012a, 2012b), a made-in-Canada language framework, the CEFR may no longer be the best option for Canada. When Vandergrift rejected the CLB/NCLC in 2006, they were in the early stages of development. The first version of the CLB (CIC, 1996) was created to address Canadian immigrants' linguistic needs. The French equivalent was created in 2002 (CIC \& CCLB, 2002) for French Canadians outside of Quebec. Since then, the CLB/NCLC have undergone several revisions as a part of the commitment by CIC "to maintain its integrity and relevance, to address gaps and to enhance its accessibility" (Bournot-Trites, et al., 2015, p. 7). For example, the CLB/NCLC's latest versions (CIC \& CCLB, 2012a, 2012 b) were developed in 2012 through a thorough process of pan-Canadian consultation and scientific validation. Moreover, these benchmarks are based on a common theoretical framework (Bournot-Trites et al., 2015) mainly grounded in Bachman and Palmer's (2010) model of language ability. Therefore, since Vandergrift's report, the CLB/NCLC (CIC \& CCLB, 2012a,2012b) have seen many revisions and a complete redevelopment, rendering obsolete many of his conclusions.

Consequently, in this paper, we argue for the use of the CLB/NCLC as an alternative to the CEFR for K-12 Canadian schools for the teaching of French and English, Canada's official languages. To this end, we first present how a language framework is necessary for curriculum development, and review Vandergrift's (2006) and CMEC's (2010) reports. Secondly, we survey the Canadian uptake of the CEFR in the education 
system to conclude that the CEFR has only been partially embraced. We then discuss the importance of context in choosing a language framework and expose the specificities of the Canadian reality. We follow by a comparison of the CLB/NCLC and the CEFR using Vandergrift's criteria for a valid language framework. We argue that the new CLB/NCLC are superior to the CEFR for use in Canada. Finally, we discuss the drawbacks of using an external framework and provide recommendations for the use of the CLB/NCLC in K-12 Canadian schools.

\section{Language Frameworks as the Basis of Language Curricula in Schools}

A framework refers specifically to a structure created to help or guide the building of something useful (Rouse, n.d.). In the case of a language framework, this might be a curriculum for teaching, an assessment, or an evaluation of language proficiency. The main goal of a language framework is to provide a common point of reference (North, 2000) to describe language for different users in various educational contexts. Hierarchies of descriptors that characterize language proficiency levels are one common point of reference. Levels in language frameworks do not describe stages in language development but language levels of difficulty (North, 2008). As North (2000) notes,

They may contain detailed content as well as outcome specifications with links made between the holistic statements appearing in the scales themselves, and guidelines consisting of lists of tasks, functions, and sometimes structures and vocabulary considered appropriate as content for each level (p. 23).

That is, the levels are ordered labels that characterize a progressive mastery of each skill, which is graded on a scale. These scales have an implied continuity of progressive proficiency with implicit thresholds that demarcate, for example, the six-level scale used by CEFR of A1, A2, B1, B2, C1, C2. The aim being that one can, for example, use the scale descriptors for the various levels to profile the content of courses, classroom assessments or large-scale provincial examinations. Frameworks incorporating continuous progression of skill levels, with thresholds separating adjacent levels on the scale, manifest themselves in curriculum planning, evaluation, and assessment.

Language frameworks are helpful to curriculum developers for conceptualizing content. Indeed, frameworks usually describe structured levels of language outcomes in terms of language tasks and the linguistic structures used in achieving those tasks. Language frameworks thus constitute a backbone of the entire scope of language pedagogy, including assessment, but they can only be as effective as they are accepted by policymakers, educators, assessors, and learners. The two frameworks under discussion in this paper are the CLB/NCLC and the CEFR. The CLB/NCLC are paired documents that provide a framework for assessing proficiency in English and French, respectively. The CEFR is designed to be used in the plurilingual European Union and is thus language agnostic. Both frameworks were developed originally for use with adult language learners and are developed to fit their local contexts.

Vandergrift (2006a, 2006b) recommended that Canadian provinces use a language framework, a point of reference to develop their own unique contextualized language 
program, including provincial curricula development and evaluation. Using a common language framework "could foster a common understanding of what functional proficiency means" (Vandergrift, 2006a, p. 7) and would bring coherence in language education amongst the provinces in the absence of a common language curriculum. It would also support the transferability of levels of language competence from one province to the next and would thus be beneficial to users, policymakers, educators and researchers. In his report, Vandergrift (2006a, 2006b) demonstrated the need for a common language framework for Canada and identified eight characteristics for a framework to be valid (theoretically grounded, empirically grounded, face validity, transparent and user-friendly, context-free and context-relevant, comprehensive, flexible and open and sufficiently discriminating of levels at the lower end of the framework). He then evaluated the existing frameworks, including the 2000 version of the CLB/NCLC (Pawlikowska-Smith, 2000), in terms of their validity and appropriateness for the Canadian context. Ultimately, he recommended that provinces and territories explore the feasibility of adopting the CEFR (CoE, 2001) for Canada.

One might wonder why Vandergrift (2006a, 2006b) or CMEC (2010) did not opt for the Canadian framework for Canada. However, the circumstances at the time motivating Vandergrift's recommendation have to be considered: the CEFR was new and had been developed with massive financial support from the CoE. The work on the CEFRbased educational products was a lot further along than that of the CLB/NCLC which were in their initial stages. Since then, however, the CLB/NCLC have gone through several revisions and validation processes. The latest 2012 versions of the CLB/NCLC (CIC \& CCLB, 2012a, 2012b) are a complete reformulation of the frameworks based on a new common theoretical framework for both the English and French frameworks. Besides, the CCLB has since spearheaded numerous projects showcasing the use of CLB/NCLC for language learning in different work and educational contexts.

Influenced by Vandergrift's work (2006), the CMEC adopted the CEFR for language learning, teaching, and assessment purposes in the Canadian context. The CMEC report (2010) compares the European and Canadian contexts in terms of language status, language policies, mobility, and curriculum, and presents the following as key considerations before using the CEFR in the Canadian context: Canadian language and cultural policies, tailoring of the descriptors and themes to K-12 learners and their validation for the Canadian context, consideration of the domain and learning situations adequate for the school-age Canadian learners, importance of social interaction among learners of different cultures and languages, research on intercultural communicative competence conducted since 1990 (in particular the notion of cultural knowledge as defined in the CEFR), characteristics of learners from immigrant background (e.g., pluriliteracy), implementation of integrated learning approaches based on inquiry and differentiated learning developed in Canada over the past decades, and, finally, the Canadian fundamental values in assessment (Joint Advisory Committee, 1993). 


\section{Canadian Uptake of the CEFR in K-12 Education}

\section{Follow up on the CMEC Recommendations}

After the CMEC endorsed the CEFR, many entities (provincial governments, school districts and associations) encouraged its use, overlooking CMEC's recommended adaptations prior to its implementation in Canadian schools. Indeed, following a forum hosted by the Canadian Association of Second Language Teachers (CASLT) in 2014 and a detailed analysis of Canadian empirical studies and practice-based projects until 2017, Arnott et al. (2017) proposed a research agenda for implementing the CEFR. The authors examined three areas of CEFR use: K-12, teacher education, and postsecondary contexts; we restrict our review to K-12.

The authors described some positive outcomes of the CMEC guidelines (2010) regarding the implementation of the CEFR in Canadian schools. They reported an increase in students' confidence and motivation amongst French L2 learners who used CEFR-based pedagogy and took the Diplôme d'études en langue française test (DELF) (Rehner, 2014). Students also appreciated some aspects of an adaptation of the European Language Portfolio (ELP), as well as the authentic and meaningful material used (Kristmanson, et al., 2013). They also reported that teachers gain from participating in formal professional learning communities to improve their understanding of the CEFR and of the European language portfolio (Kristmanson et al., 2011; Mui, 2015). Other studies, however, reported "little or no knowledge of the CEFR" (Mison \& Jang, 2011, p. 102) amongst teachers from Ontario, and warned about teachers simplifying the application of the CEFR because of gaps in their knowledge and understanding of the instrument, which would distort it (Piccardo, 2013).

Arnott et al. (2017) also report on other shortcomings of the CEFR's use in Canadian classrooms as highlighted by research studies. Plurilingualism, for instance, is a basic concept in the CEFR. In the Canadian context, however, Taylor and Cutler (2016) show that in French as a second language (FSL) classrooms, teachers insist students speak French only. Lyster (2019) explains this phenomenon by arguing that translanguaging or cross-linguistic pedagogy cannot be applied without caution in FSL classrooms in Canada where English is often the default dominant language. Self-assessment, another key concept of the CEFR, was not always positive for students' learning either. Finally, Arnott et al. reiterated that several authors have stated that the CEFR levels needed to be divided into sub-levels: Gauthier (2015) has shown that students have difficulties appreciating their gains when using the levels because they may have improved in proficiency but have not moved between CEFR bands in an assessment.

Therefore, it appears that most of CMEC preoccupations regarding the use of CEFR in Canada are yet to be addressed. Meanwhile, some schools and teachers use the CEFR as is, with their limited understanding of it. This adoption by many teachers may give the impression that the CEFR is commonly used; however, nobody knows exactly how many students are trained in the "CEFR system" (Jezak \& Piccardo, 2017, p. 21). 


\section{Uptake by Canadian Curricula}

Another issue highlighted by Arnott et al. (2017) is that the guidelines are proposed at the federal level, but education in Canada is regulated at the provincial level. To investigate the use of the CEFR at the provincial level, we surveyed the K-12 provincial L2 curricula.

On the French side, although all provinces, except Alberta and Québec, have implemented new FSL curricula since CMEC's 2010 recommendation, only the Atlantic provinces referred to the CEFR. In 2010, the FSL Directors of the four Atlantic provinces decided "that all newly developed curricula would be based on the CEFR and its descriptors" (New Brunswick Ministry of Education, 2011, p. iii). However, neither the Newfoundland and Labrador (see Appendix) nor the Nova Scotia curricula refer to the CEFR. Only New Brunswick (NB) and Prince Edward Island (PEI) followed the CMEC guideline. The 2018 NB immersion curriculum for grades 8-11 uses the CEFR's five communicative activities as a framework for learning outcomes and I can descriptors, and presented a table showcasing links between the school grade levels and the CEFR levels. It also created a CEFR-based language e-portfolio (Kristmanson et al., 2011). As for PEI, the curriculum document indicates the CEFR as a guide, especially in the learning outcomes design.

Ontario's Framework for FSL (Ontario Ministry of Education, 2013) recognizes CEFR as a means to inform teaching and assessment. However, the 2014 FSL curriculum itself does not refer to the CEFR nor does it seem shaped by it. Still, a "think tank" composed of six regional and provincial leads in collaboration with the Ontario Ministry of Education states that the CEFR is embedded in the curricula's enduring ideas and that 60 school boards have adopted it (CEFR Ontario, n.d.). In British Columbia (BC), although a draft curriculum based on the CEFR for all L2s including French (Wernicke-Heinrichs \& Bournot-Trites, 2011) was launched in 2010, the latest curriculum, put in place between 2016 and 2020, is not based on the CEFR and does not allude to it.

On the English as a second language (ESL) side, in Saskatchewan, the CEFR has been heavily adapted into the Common Framework of Reference (CFR) and an extensive document was developed for its use with English language learners (Saskatchewan Ministry of Education, 2013). In BC, the ELL Standards (BC Ministry of Education, 2017) acknowledge that material from the CEFR as from other sources was adapted. Curricular documents produced from other provinces after 2010 (i.e., Manitoba, Newfoundland and Labrador, and PEI) do not refer to the CEFR.

Therefore, it seems that the CEFR is used, at least in some provinces for FSL (NB, PEI, Ontario) and for ESL (BC, Saskatchewan), but not all provinces have adopted it. Based on our survey, other modern languages (e.g., Chinese, German, Spanish) provincial curricula do not refer to the CEFR.

Despite an unbalanced implementation in provincial curricula across the country, the CEFR has benefited from the support of professional associations, especially in French. CASLT has developed a CEFR kit for educators and administrators with teaching assessment tasks and resources, such as the CFR and the Canadian Language Portfolio (for students or for teachers). Other supporting materials, such as the Action Oriented Handbook (bilingual) are also available on their website (www.caslt.org). This effort to 
support the use of CEFR in Canada has mainly been made possible with the financial support of Canadian Heritage, which has not been available to the CLB/NCLC.

To sum up, the CMEC considerations for adopting the CEFR are yet to be fulfilled. Given the lengthy and costly adaptation measures that the CEFR would require to be successfully adopted in Canadian schools, a Canadian-made framework, such as the CLB/NCLC, that tackles the particularities of the Canadian context and addresses local sensitivities presents itself as a logical alternative. Using the Canadian framework is in fact a way to reduce the adaptation cost and to, mostly, ensure that the framework is true to Canadian perspectives.

\section{Towards a Recognition of the Value of a Canadian-Made Framework}

\section{Rationale: The Importance of Context}

Communicative competence stems from a sociolinguistic view of language where the context is extremely important. According to Van Dijk (2009), "contextual constraints affect all levels and dimensions of text and talk" (p.205). Likewise, motivated by the work of Zumbo and his colleagues (Zumbo, 2009, 2015, 2017; Zumbo et al., 2015), there is a growing recognition of the important role that context plays in assessment design and test validation especially when using a communicative or action-oriented approach to teaching as supported by the CEFR. Indeed, the CEFR document (CoE, 2001) affirms that the scales are examples that can be used in different ways and that they are "a tool for future planning and a basis for further development" (p. 36), both for teaching and for assessment. Therefore, in order to evaluate the extent of adaptations needed for this framework to be used in Canadian schools, it is important to point out significant differences between the Canadian and European contexts of use.

Contemporary assessment design and validation highlight that differences such as those between the Canadian and European contexts of use are at the centre and are not peripheral matters to assessment practice. That is, in terms of assessment design and validation, Zumbo (2015) introduced the distinction between in-vivo and in-vitro views of assessment (comparable to the concept of "authenticity" in language pedagogy) displacing the outworn tenet that assessment practice and validation could somehow occur in-vitro, as if isolated from its cultural and ecological settings, and sources of influence that occur in real-life operational contexts. The European framework is situated in the noncontemporary in-vitro and context-free perspective. The in-vivo view draws the authenticity of pedagogy, assessment, and curriculum naturally into the Canadian language framework.

\section{The Canadian Context}

With global readership in mind, it is of value to make a few remarks about the in vivo Canadian context. Canada's specific social and political history influenced both its language and multicultural policies and its L2 education system. Each will be discussed in turn. Given the minority status of French in Canada, the discussion will have an emphasis on this language. 


\section{Canada's Linguistic and Multicultural Policies}

In 1963, in the light of concerns with the distressing condition of the French language and the francophone minority in Canada and with the growing nationalist sentiment in Québec (Haque, 2012), Prime Minister Pearson launched the Royal Commission on Bilingualism and Biculturalism Commission (B and B Commission, 1968) with the mandate to report upon the situation of bilingualism in Canada and on the opportunities available to Canadians to learn English and French (Yalden, 2013, p. 9). One of the 150 Commission's recommendations resulted in the 1969 Official Languages Act which established French and English as Canada's official languages as well as their equality of status (Section 2). However, this status equality is a matter hotly debated in Canadian politics as French is de facto a minority language in Canada and has an unequal power relation with English. Both because of numbers (i.e., a higher proportion of English speakers) and because of the political context (e.g., the 1759 British conquest), the English speakers have had greater power in the country (Heller, 1999). Following the rise of nationalism in Québec, the Québec provincial government adopted la Charte de la langue française at the end of the 1970s. The vision embodied in the Charter was that "Quebec should behave publicly as a monolingual zone, and with a language whose quality guarantees the worth of its speakers" (Heller, 1999, p. 156). Consequently, according to Heller, both the federal government and the francophones hors Québec had to redefine their place and identity. The federal government started cultivating a new image away from the British Empire and more sympathetic to the country's francophone minorities, recognizing them as one of the two founding nations (Heller, 1999).

In line with this new image, the Canadian Multiculturalism policy was introduced in 1971. Although seen as positive, this policy avoided discussions of historical injustices and ignored input from Indigenous leaders (Haque, 2012). In 1988, the Parliament adopted the Canadian Multiculturalism Act which recognizes and promotes the understanding that multiculturalism is a fundamental characteristic of Canadian heritage and identity. Decades of multicultural policies in Canada helped develop an ideology according to which multiculturalism is an integral part of, and even defines Canadian identity (Frost, 2011) and its support by Canadians is strong (Kymlicka, 2008, Soroka \& Roberton, 2010). However, support for multiculturalism does not necessarily mean support for cultural recognition; most Canadians prioritize immigrants' integration in the society (Reitz, 2014). For Hansen (2014) "Canada has an assimilation policy masquerading as a multicultural policy" (p. 74). For him, multiculturalism allows Canadians to define their identity and the essence of who they are in support of "their eternal [...] quest: not being American" (p. 84). To many, Canada's pluralist mosaic, which assumes equality of powers, in fact, hides unequal relationships amongst communities (Heller, 1999; Kubota, 2004), including that of French vis-à-vis English. In spite of multiculturalism policies, English speakers still have greater power in the country.

On the other side, Canadian French varieties often face prejudice vis-à-vis European French. From various sociohistorical reasons including the notion of le bon usage as it appeared in the $17^{\text {th }}$ century, French has been seen as a monocentric language, that is, as a language with a sole norm (Bourhis, 1997). Consequently, varieties of French that diverge from the norm, such as those in Canada, have often been regarded as incorrect or of lower status. For example, Kircher (2012) has found that, since the 1980s, attitudes 
towards Québec French regarding its status have not changed. In her study, the 157 students from Montréal cégeps who answered the questionnaire seemed to view Québécois French as less positive than European French.

In the case of French, adopting a framework developed in Europe (with its associated assessment tools) could reinforce this monocentric ideology of European French. Oakes and Peled (2017) proposed the concept of pluricentric linguistic justice concerned with "the just distribution of power, of linguistic advantages and burdens, in a language with multiple production centres" (p. 115). Such ideology would not only recognize Standard Québec French but also various varieties of French in Canada (see Papen, 1998, for a description of Canadian varieties of French). In a situation where a language (here Canadian French) is in a situation of unequal powers (vis-à-vis both English in Canada and European French), its locutors may face linguistic insecurity which eventually leads to the language decline (Klinkenberg, 2015). A possible solution to such a phenomenon is to increase the language's legitimacy. This can be done by institutionalizing the language norms (Klinkenberg, 2015; Oakes \& Peled, 2017), such as adopting the CLB/NCLC in Canada.

\section{Language Education in Canada}

Influenced and shaped by Canada's social and political history, and linguistic policy, is Canada's educational landscape. In Canada, education is of provincial jurisdiction; each province and territory is responsible for the design and implementation of programs and curricula and for the assessment of its pupils. That being said, official minority language and L2 education is important in all provinces as it is promoted, protected and funded by the federal government.

In addition to the issue of official languages, the B and B Commission made many recommendations regarding minority language education. Before the commission, instruction in the mother tongue was deficient for the French minorities outside of Québec (Aunger, 2001, 2005, Hayday, 2013). Even in Québec, the English Protestant system was better funded than the French Catholic one (Hayday, 2013). The commission recognized the importance of mother tongue education for community vitality, but it is finally through the Canadian Charter of Rights and Freedoms, Part 1 of the 1982 Constitution Act, that minority language educational rights were guaranteed (Canadian Charter of Rights and Freedoms, 1982, s 23).

The B and B Commission also had recommendations regarding individual bilingualism. Commissioners considered that second official language learning would help cultural understanding between Canada's linguistic groups while increasing the number of bilingual Canadians that can work in both official languages (Hayday, 2013). Moreover, in his fifth report, the Commissioner of Official Languages recommended the "youth option", which involved "shifting the focus of language policy to effective language education for children, so that they would grow up to become bilingual adults" (Hayday, 2013, p. 32). The federal government supported such recommendations by contributing a portion of the cost of provincial second official language education through the Official Languages in Education (OLE) program (Early et al., 2017); since 1970, over $\$ 7$ billion has been spent by this program (Hayday, 2013). 
This massive investment in second official language education contributed to the explosion of various forms of French Immersion (FI) programs across the country since the 1970s (Dicks \& Genesee, 2017). Although these programs are very popular across the country, the majority of K-12 students (i.e., 85\%) learning FSL are in Core French, a program in which lack of intensity and of teacher expertise has brought less than optimal outcomes (Early et al., 2017, p. 7). On the ESL side, young francophones living in Englishdominant provinces usually learn English with no problem at school and in their community. In Québec, the rise of the United States and of English as lingua franca in the globalized world reinforces the need and desire for young francophones to learn this L2. K12 newcomers to the country also learn an official language and are enrolled in English language learning programs (ELL) in English schools or in classes de francization or classes d'accueil in French schools. However, these programs do not benefit from a "panCanadian, coherent, federal profile of policies, programs, and provisions" (Early et al., 2017, p. 3). The adoption of the CLB/NCLC in the Canadian context would give such a coherent framework. It would also give a common standard to measure students' competence and assess the efficacy of the important sums of money invested in L2 education.

\section{CLB/NCLC versus CEFR}

A thorough comparison and alignment/linking study of the CLB/NCLC and the CEFR was conducted by North and Piccardo (2018). This report appears to be the first study of the comparability of the two frameworks to include quantitative metrics (in the form of Multi-Faceted Rasch Modelling) in addition to expert opinion. The report also refers to two commissioned reports (Bournot-Trites et al., 2018 and Dicks, 2018) which support the theoretical justification for performing a linking study of the CLB/NCLC and the CEFR. The conclusions were overall positive with respect to the quality of both frameworks and the functionality of alignment between them. The success of the scale linking appears due largely to the many similarities between the CLB/NCLC and the CEFR.

Before proceeding to discussion of which framework better meets the CMEC recommendations, it is appropriate to compare the structures of the CEFR and the CLB/NCLC. The CEFR has a total of 10 levels (initially 6) grouped into three stages A, B, and $\mathrm{C}$ while the CLB/NCLC have 12 levels (called benchmarks) also divided into three stages. The CLB/NCLC are based on the usual four linguistic skills: listening, reading, writing and speaking. The CEFR is based on communicative activities, which comprise the skills of listening and reading, but further divides both writing and speaking in production (i.e., writing an essay, presenting in front of an audience) and in interaction (e.g., writing an email, having a discussion). Rather than list the many theoretical, developmental, and practical similarities between the frameworks (See North \& Piccardo, 2018, for an extensive review), we will focus on specific points of interest worthy of discussion.

First, in North and Piccardo's content analysis comparison, a structural difference was noticed. The CEFR level descriptors use a salient feature approach where the descriptors are all fully independent from the previous or succeeding levels. In contrast, the CLB/NCLC uses a system wherein the differentiation between levels is marked by a systematic semantic progression using qualifiers such as "occasionally", "sometimes", 
"usually", "often", and "always" as the distinguishing feature between proficiency levels (North \& Piccardo, 2018, p. 4). This structural difference is by design and reflects the differences in development methodologies between the two frameworks. It reflects the different philosophies of the organizations involved in developing their respective frameworks.

In the $\mathrm{CLB} / \mathrm{NCLC}$, the benchmarks are presented in a common format that stems from the theoretical framework, and levels of competence in various contexts for each of the four skills are described. This common format lends itself strongly to the development of curriculum and learning resources. The CEFR, on the other hand, provides a great diversity of tasks and domains presented in numerous concise descriptive tables (detailing the $\mathrm{A} 1$ to $\mathrm{C} 2$ levels of proficiency) for many possible situations in a variety of language domains or specific language activities. This diversity, which does lend itself well to the creative aspects of pedagogy, results in an impression of less cohesion than in the CLB/NCLC.

Because the CEFR contains such a wide variety of tables it can be difficult for teachers to create a unified course curriculum using this framework. While the CEFR supporting documents are developed in such a way that they provide many diverse and specific examples demonstrating how certain language tasks can be mapped to the CEFR scale, it can be difficult to integrate these many diverse language tasks into a consolidated curriculum. According to Dicks (2018), the CEFR presents "can do" statements that may or may not contain indicators of the communicative context or the language learner's specific strengths and weaknesses for a particular level. In addition, although the CEFR does officially reference 10 levels, not all levels are represented in each exemplar language task; some tables only present the six initial reference levels. As a result, a smoothly progressing language curriculum is not assured when using the CEFR. A great deal is left to the creativity of the teacher (Bournot-Trites et al., 2018, p. 5), creating extra pedagogic work that will often be duplicated between classrooms, and reducing the comparability of different classrooms.

Fulcher (2004a) explains that since the CEFR is designed to work across languages, the objectives have to be general which makes the framework a model rather than a framework. North (2004) notes that the CEFR does not define what should be taught and how it should be taught. Furthermore, Little (2007) states that the scales are not organized hierarchically, and the users/teachers have to decide which scales are adequate for their purpose. These points show that the CEFR is not teacher-friendly and requires a lot of supplementary work to design a curriculum or even a unit plan. This could explain why teachers who use the CEFR often only use the "general competency" scale of the CEFR, as opposed to its many task-specific scales.

In contrast, each of the $12 \mathrm{CLB} / \mathrm{NCLC}$ benchmarks describes in detail the knowledge (grammatical, textual, pragmatic) necessary to accomplish communicative tasks at that level. These benchmark descriptions are made clear by using three distinct types of descriptors for each benchmark profile: "can do" statements; a delineation of the communicative context (When the communication is ...); and, specific strength and limitations of the learner (Dicks, 2018, p. 24). The situation parameters are also stated, as well as the criteria for observing that ability. For each stage of each skill, there is a list of required strategic competence and grammatical, textual, functional, and sociolinguistic knowledge. These descriptors closely follow Bachman and Palmer's (2010) model of 
language ability, which will be discussed more in the following section. Thus, using the CLB/NCLC in Canadian schools ensures that the requirement of the CMEC of determining a language competence development model is fulfilled. This clear, detailed and unified progression in the CLB/NCLC makes it simpler for teachers to plan a course than with the CEFR which tends not to have the same level of specificity.

While the North and Piccardo (2018) linking map between the CLB/NCLC and the CEFR appears to have been successful, it is too soon to see how the link will be used in practice. This is because, although the two frameworks have many theoretical similarities (Bournot-Trites et al., 2018), the different ways in which they were developed resulted in products that are naturally used differently by educators. These differences between the CLB/NCLC and the CEFR do not make one framework inherently better than the other. They are reflective of the different purposes for which they were created and make each useful in different contexts. In the Canadian ESL and FSL contexts of K-12 language education, the CLB/NCLC appears to be better suited.

\section{Reviewing CMEC Considerations}

In choosing to recommend the CEFR for use in Canadian K-12 education, the CMEC highlighted several factors to be considered prior to adoption. One major recommendation was to create more levels for increasing discrimination at the lower-end of the CEFR scale to facilitate the education of school-age students. This was important because, at the time, the CEFR had only the six primary reference levels. This has since been addressed with the addition of four sub-levels. However, as was discussed in the previous section, these four sub-levels are not represented in all of the CEFR exemplar scales. In order to use the CEFR effectively in K-12 education, the CMEC recommendation to increase discrimination at the lower end of the scale is still relevant.

Another CMEC recommendation was about the accessibility of a portfolio system for tracking language progression. Both CLB/NCLC and CEFR currently have a portfolio system, but they are not school-specific portfolios. For both frameworks, a school-based portfolio system accepted by the university for entrance purposes would need to be created. The advantage of the CLB/NCLC in this regard is that the portfolio system is intended to be an act of co-creation between learners and teachers following an approach of assessment for learning (CCLB, n.d.) which may make adaptation to a school-based system simpler than the CEFR portfolio.

When considering the CMEC recommendations for validating the use of the CEFR in Canadian schools, the CLB/NCLC have other advantages. Unlike the CEFR, the CLB/NCLC are based on Bachman and Palmer's theoretical framework (2010). In Bachman and Palmer's model, language ability includes language knowledge and strategic competence. Language knowledge is subdivided into organizational knowledge (including grammatical knowledge and textual knowledge) and pragmatic knowledge (which includes functional knowledge and sociolinguistic knowledge). Strategic competence refers to elements of metacognitive competence: goal setting, appraising and planning. The use of Bachman and Palmer's model in the CLB/NCLC is important because the CMEC also recommended that the framework be used in Canadian K-12 education ought to be grounded in a language competence development model. 
When considering the requirement of adapting the CEFR to the Canadian context and including cultural and intercultural competencies, it is important to note that the $\mathrm{CLB} / \mathrm{NCLC}$ are based on Canadian culture and address intercultural competence. As noted by Dicks (2018) in his report, the CLB/NCLC have descriptors such as "understanding features like verbal humour, low-frequency idioms and cultural references" which appear as early as CLB-9, but there is no reference to these elements at all in the CEFR descriptors" (p. 11).

In summary, neither of the two frameworks is fully ready for use in the Canadian K-12 school context. However, the CLB/NCLC, already anchored in a Canadian perspective and meeting the primary recommendations of the $\mathrm{CMEC}$, would require less effort and resources to be adapted to this specific population.

\section{Vandergrift's Criteria for a Valid Framework}

Given our conclusion, one might wonder why Vandergrift (2006a, 2006b) recommended the use of the CEFR over the CLB/NCLC. Vandergrift stated, correctly at the time, that the CLB/NCLC "were created for adult immigrants who are developing language skills for entry into the Canadian workforce, the CLB are not suitable to school contexts without significant adaptation" (p. 20). This is often the first reason given for not using the CLB/NCLC in schools. However, Little (2007) pointed out that adapting the proficiency levels to younger learners represents a challenge for the CEFR and Alderson (2007) also stated that "the CEFR is not suitable for young learners" (p. 661). Moreover, Figueras (2007) declared that some tasks in the CEFR are beyond the cognitive and experiential level of children and many adolescents. The choice to use the CEFR over the $\mathrm{CLB} / \mathrm{NCLC}$ is therefore less justified by supposed adequacy for younger learners than was previously thought.

In addition, since the original evaluation by Vandergrift (2006a, 2006b) and the CMEC (2010) recommendations, the CLB/NCLC has been substantially revised. We argue that, since these revisions, Vandergrift's primary rationale for rejecting the CLB/NCLC as a suitable choice for the common language framework in Canada no longer holds. He discussed eight criteria required for a common language framework to be valid in Canadian K-12 education. We review these criteria in the light of the 2012 CLB/NCLC.

\section{Theoretically Grounded}

The 2012 CLB/NCLC are based on Bachman and Palmer's (2010) model of language ability. As described earlier, the architecture of Bachman and Palmer's model appears clearly on each page of the benchmarks.

In contrast, the CEFR is based on the theory of communicative competence without adhering to any specific model. However, there is no apparent link to a communicative competence framework noticeable from the framing of scales in terms of "can do" statements (Weir, 2005). Explaining how the CEFR was developed, Fulcher (2004b) states that the designers used 30 rating scales that were not based on any theoretical framework where teachers were instructed to sort 2000 level descriptors into three groups: low, medium and high. Then, the teachers were instructed to evaluate whether the descriptors were below, at, or above the level of their students. The results were then subjected to 
statistical analyses to estimate their level of difficulty, mapped to a six-level scale, and cut points were thus defined. Fulcher concludes that "The CEF has no underlying theory and no content specifications. Many tests that are now claimed to be linked to the CEF do not themselves have a theoretical basis. The "“linking" is mostly intuitive" (p. 7).

\section{Empirically Validated}

Vandergrift (2006a, 2006b) found that the previous version of the CLB/NCLC was insufficiently empirically validated. The revised CLB/NCLC has been used and studied extensively in the context of Canadian immigration and citizenship.

The Ministry of Immigration, Refugees, and Citizenship Canada (formerly CIC), through the CCLB, has carefully considered the CEFR when developing the 2012 versions of the CLB and NCLC. The validation of the Canadian benchmarks included a comparison with the CEFR, as well as with the American Council for the Teaching of Foreign Languages (ACTFL, 1982) guidelines, and the Échelle québécoise (Gouvernement du Québec, 2011). These comparisons showed that the theoretical framework was consistent not only with the theoretical concepts it articulated but also with the key principles underlying other language frameworks. Recently, the North and Piccardo (2018) report aligned the CLB with the CEFR. This was possible because both frameworks describe language competence in similar terms from a beginner level to a highly advanced level following a number of stages showing increasing complexity in the use of the language. Further validation should be conducted for use in the K-12 education context.

\section{Face Validity}

The CLB/NCLC are developed specifically to reflect the Canadian context. This, in combination with it having been developed by subject matter experts intimately familiar with the needs and desires of Canadians, means that it has strong face validity for use in the Canadian context.

\section{Transparent and User-Friendly}

Vandergrift (2006a, 2006b) found that the previous version of the CLB/NCLC was insufficiently transparent and user-friendly. In its new format, the CLB/NCLC is extremely user-friendly to a wide variety of stakeholders. The new format contains both single-page summaries of each benchmark and in-depth, detailed specifications of the communicative competence of language users at each benchmark.

This is an area where the CLB/NCLC appears to be preferable to the CEFR. As discussed in the previous section, the CLB/NCLC are organized in a highly consistent and structured manner. In contrast, the CEFR has areas of less consistency in the level of detail with which levels of proficiency are described. The CEFR as a document is also less userfriendly for navigation, with various tables detailing language activities spread throughout the large framework documents (e.g. the 2001 initial framework and the 2018 companion volume). 


\section{Context-Free/Context Relevant}

The CLB/NCLC are context rooted. The progressive descriptions of the benchmarks in the CLB/NCLC include a specification of the context in which a task is to be performed, further differentiating the CLB/NCLC from the CEFR, which aims to exclude the consideration of context in its specification of language tasks (Weir, 2005). The Canadian culture and context are also central to the formulation of the CLB/NCLC as they are intended to act as a Canadian framework. This is a shift away from prior ways of thinking which guided the CEFR towards attempting a context-free approach, and which informed Vandergrift's (2006a, 2006b) assessment of the qualities which make an ideal framework. As discussed above, we argue that treating context as "pollution" in assessment is an outdated concept. Instead, acknowledging the role and value of in-vivo style context in language teaching and assessment is a key feature of measure validation (Zumbo, 2017) and a framework that acknowledges context provides a scaffold for pedagogy and assessment functioning in a similar manner.

\section{Comprehensive}

Vandergrift (2006a, 2006b) found that the previous version of the CLB/NCLC was insufficiently comprehensive. In its new format, the CLB/NCLC covers the full spectrum of communicative competence. The framework also provides detailed specifications at each benchmark for each of the four language skills which are covered under the Bachman and Palmer (2010) model of language ability. This is another area where the CLB/NCLC appear to have an advantage over the CEFR. The CLB/NCLC have greater consistency in their specification.

\section{Flexible and Open}

Vandergrift (2006a, 2006b) found that the previous version of the CLB/NCLC was insufficiently flexible and open. In its new format (CIC \&CCLB 2012a, 2012b), the CLB/NCLC provides a framework that enables an in-vivo approach to assessment and for informing language pedagogy. By acknowledging context and culture as an intrinsic part of language, users of the CLB/NCLC are not required to artificially attempt to control for the "pollution" of context, increasing its utility and flexibility within the Canadian context.

\section{Sufficiently Discriminating of Levels at the Lower End of the Framework}

The CLB/NCLC are most discriminating at lower levels. This finding was validated in the North and Piccardo (2018) report.

Taken altogether, according to Vandergrift's (2006a, 2006b) eight criteria of a valid language framework, the CLB/NCLC are now on a potentially equal or superior footing with the CEFR in terms of the requirements laid forth by Vandergrift. Both the CLB/NCLC and the CEFR will require further adaptation to be fully appropriate for use in K-12 education. However, the revised CLB/NCLC meet all of the requirements of a valid framework as stated in Vandergrift. In certain areas, in our assessment, the CLB/NCLC have an advantage over the CEFR. 


\section{Discussion and Recommendations}

It seems surprising to us that a country that has invested in developing a language framework at the national level has turned to other frameworks for adoption in its schools. When CMEC recommended the use of the CEFR in schools, it did so with acknowledgement of the fact that the CLB/NCLC were, at the time, less well developed, despite being a Canadian option.

As explained previously, the CEFR was recommended because Vandergrift (2006a, 2006b) made a strong, research-based case for it. However, at that time, the first CLB and NCLC versions had many conceptual flaws that made them weaker frameworks. These flaws came up clearly in the 2009 consultations commissioned by the CCLB (BournotTrites et al., 2015). The results of these consultations prompted the government to revise and redevelop the Canadian framework, with specific consideration for the NCLC being sensitive to the French minorities' issues in Canada. In 2020, the situation is different from that of Vandergrift in 2006, or of CMEC in 2010, and the recommendations ought to be changed, as we have argued.

Despite Vandergrift's and the CMEC's recommendations, not all provinces have adopted the CEFR as a basis for their curricula, although many school boards use the test Diplôme d'études en langue française (DELF) in their jurisdictions for grade 12 French immersion school students. Nova Scotia has adopted the DELF as a provincial FSL proficiency test and Vandergrift (2015) reported the constant increase of DELF tests taken in Canada. Harlaux and Georges (2012) have stated that 89 diplomas were awarded in 2005 compared to 2,920 in 2011; these numbers have probably increased in the same way since. For students and their parents, the DELF validates the students' learning of French during their school years, so much so that a large proportion of parents responding to a questionnaire said that they would be willing to pay at least part of the test cost (Vandergrift, 2015). This move towards the DELF demonstrates the unfortunate lack of a formal Canadian-made French test for graduating grade 12 students.

Regrettably, the decision to choose a European-made test for Canada represents some dangers. Shohamy (2001) has long recognized the power of tests on societies. In the same way, McNamara (2010) asserts that more and more tests are used as instruments of policy and discusses the issues of validity related to this. Looking towards the mother countries for language standards in our country is accepting linguistic, cultural and educational imperialism (Phillipson, 1992, 2010). This can lead to the pernicious linguicist effect of elevating European linguistic varieties over Canadian ones (Canagarajah \& Said, 2011), which is especially a risk for Canadian French minority varieties. In turn, due to these linguistic hierarchies, the Europeanization of language in Canada brings a risk of losing language diversity and cultural specificity (ironically, at a time where linguistic diversity is celebrated). Fulcher (2004a) brings up the dangers of frameworks being institutionalized. One of the goals of the CEFR is the harmonization of language teaching and testing amongst European states. As stated by Fulcher,

In language testing, as in other policy areas, it is therefore critical to be aware of harmonization that may lead to further political unification by stealth, irrespective of whether the framework is a suitable tool for this purpose or not (p. 264). 
An explicit example of this linguistic imperialism in the Canadian context is shown by examining the effects of the implementation of the DELF. Inspired by two studies conducted by the Ottawa-Carleton District school board (OCDSB, 2010, 2011, cited in Vandergrift 2015) about the use of the DELF exam in schools, Vandergrift conducted a similar study with participants (students, teachers and parents) across Canada mostly from Alberta but also from Ontario, BC and Nova Scotia. In this study, Vandergrift found that taking the test increased the motivation of students for learning French. Classroom activities were shown not to differ much from test tasks. However, about $51 \%$ of students found that the cultural references interfered with their achievement. On the other hand, $81 \%$ of teachers felt that cultural references might interfere with their students' success. Students also found that listening and speaking tasks were the most difficult. After using the DELF for their students, teachers indicated that they now understand the test better, and that they may change the types of activities they conduct in class. Moreover, Vandergrift concludes that teachers need to adjust their teaching to make tasks more authentic. Yet, authenticity is related to a cultural context. Does it mean that French language teachers need to use material coming from France to make those activities more authentic? In point of fact, teachers indicated that the use of the DELF had a washback effect, changing their pedagogy. Teachers feel the need to harmonize their teaching with the content of the test, including the cultural content.

The expanding use in schools of the DELF junior/scolaire, an examination sanctioned by the French Republic's ministère de l'éducation nationale, already calls for language from France and Europe-centered cultural content. A corollary of this is the use of CEFR-designed books and methods from Europe without any Canadian cultural or linguistic context. The interrelation between culture and language and the importance of culturally appropriate texts have been largely discussed in the literature (Kramsch, 1988, 1993, 2013). The ramifications of ignoring such literature should not be underestimated in Canada, especially in view of the French minority situation. By turning to foreign frameworks, assessments and texts, we indoctrinate our students to believe that French or English varieties from Europe are better than what we speak in Canada and they will want to use models from France or England to succeed on tests coming from Europe.

Another danger of using curricula, manuals, and assessment coming from France claiming to be levelled according to the CEFR is that there is no evidence of a relationship between those manuals and the CEFR (Alderson, 2007). In reality, "the Council of Europe has refused to set up an equivalent mechanism to validate or even inspect the claims made by examination providers or textbook developers" (Alderson, 2007, p. 661).

The use of the national frameworks, the CLB/NCLC, is therefore important to promote Canadian linguistic sovereignty, and cultural and linguistic specificity and diversity. Then what stops us from adopting the CLB/NCLC in Canadian schools? The CEFR has momentum and means. Many resources, financial and others, come with the CEFR. Europe has embraced the CEFR with a huge financial investment and some countries around the world have followed Europe's lead. A bibliometric analysis by Runnels and Runnels (2019) shows CEFR with over 16,000 citations since its formation. In Canada, where funding has been available for research into the CEFR, there has been no willingness or financial support on the part of the government to adapt the CLB/NCLC to K-12 education and to pilot and validate it for K-12 instructional contexts. A Google Scholar citation search yields only 126 counts for the "CLB"- - this is despite the failure of 
the Google Scholar to distinguish between the documents mentioning the "CLB" or investigating them. One thus wonders why the federal government does not invest in developing resources for Canadian K-12 teachers based on its own framework. In the absence of research evidence into the adaptability of the CLB/NCLC, the educational system may support the CEFR for FSL as well as ESL at the risk of colonizing Canada's linguistic landscape.

Several recommendations can be made from our analysis. Without a doubt, there is a need for more promotion and visibility of the CLB/NCLC by the CCLB supported by the $\mathrm{CMEC}$ and the federal government. Communication and knowledge dissemination about the CLB/NCLC are needed in schools and in professional associations. One way to promote the Canadian language framework is to conduct more research about it. However, financial support is needed to develop more tools for the CLB/NCLC and to validate it for $\mathrm{K}$ to 12 . Another way is to create a language test for grade 12 students based on the CLB and NCLC. A key point emphasized in Zumbo and Hubley (2017) is the need to develop contextualized and dynamic assessment frameworks that take into account the situational, cultural, and ecological aspects of testing when exploring test design and validation. A Canadian test based on a Canadian language framework would be consistent with the importance of taking into account context when designing tests. While the CLB/NCLC portfolio can be used as formative assessment, a national language test would validate the students' achievement and would motivate them to study language. Such a test would encourage teachers to turn to the Canadian framework to design their teaching units and provinces to base their curricula on the CLB/NCLC.

Practitioners have used the CMEC 2010 recommendation to justify the use of the CEFR without paying attention to all the conditions stated after the recommendation or to the consequences of using a foreign language framework. With all the work done to develop and validate the 2012 Canadian framework and its advantages for use in Canada, one would expect a government to support and develop further the use of its own language framework. Finally, CMEC could revisit its recommendations from 2010.

At the conclusion of their 2017 article, Arnott et al. wrote: "The use of the CEFR in the Canadian context, then, clearly requires the engagement of multiple stakeholders at various levels, including policy, professional development, pedagogy, and learning." (p. 47-48). If this is true for the CEFR that has already achieved a lot in Canadian schools, the same and more could be said about the CLB/NCLC. For this to happen, the Canadian government and all stakeholders would need to refuse linguistic, cultural and educational imperialism and adopt their own language framework. As the proverb goes, it is common that prophets are not accepted in their own land. In spite of apparent reticence to adopt the CLB/NCLC, Canadian learners and teachers of language would benefit greatly from an increased use of this framework. While the CEFR has many positive qualities, in Canada, where culture and heritage are treasured, the CLB/NCLC are the stronger frameworks for the Canadian K-12 educational context.

Correspondence should be addressed to Monique Bournot-Trites.

Email: monique.bournot-trites@ubc.ca 


\section{Acknowledgements}

We would like to thank the anonymous reviewers for their constructive and thoughtful feedback on this article.

\section{References}

American Council for the Teaching of Foreign Languages (ACTFL). (1982). Provisional proficiency guidelines. Hasting on Hudson.

Alderson, J.C. (2007). The CEFR and the need for more research J. Modern Language Journal, 91(4), 659-663.

Arnott, S., Piccardo, E., Brogden, L. M., Rehner, K., Faez, F., Taylor, S. K., Peguret, M., Wernicke, M. (2017). The common European framework of reference (CEFR) in Canada: A research agenda. Canadian Journal of Applied Linguistics, 20(1), 31-54.

Aunger, E. A. (2001). Justifying the end of official bilingualism: Canada's North-West Assembly and the dual-language question, 1889-1892. Canadian Journal of Political Science/Revue canadienne de science politique, 34(3), 451-486.

Aunger, E. A. (2005). De la répression à la tolérance: les contrariétés du néolibéralisme linguistique en Alberta. In J. Wallot (Ed.), La gouvernance linguistique: Le Canada en perspective (pp. 111-126). Les Presses de l'Université d'Ottawa.

Bachman, L. F., \& Palmer, A. (2010). Language assessment practice: Developing language assessments and justifying their use in the real world. Oxford University Press.

Bourhis, R. Y. (1997). Language policies and language attitudes: Le monde de la Francophonie. In N. Coupland \& A. Jaworksy (Eds.), Sociolinguistics: A reader and coursebook (pp. 306-322). Palgrave Macmillan.

Bournot-Trites, M., Barbour, R., Jezak, M., Stewart, G. \& Blouin Carbonneau, D. (2015). Theoretical framework for the Canadian language benchmarks and niveaux de competence linguistique canadiens. Centre for Canadian Language Benchmarks.

Bournot-Trites, M., Friesen, L. \& Ruest, C. (2018). Report on the correspondence of the Canadian Language Benchmarks/Niveaux de compétence linguistique canadiens versus the Common European Framework of Reference for Languages for The Centre for Canadian Language Benchmarks/Centre des niveaux de compétence linguistique canadiens under the project RESCEFR-18: Aligning the Canadian Language Benchmarks (CLB/NCLC) and the Common European Framework of Reference (CEFR).

British Columbia Ministry of Education. (2017). Province of British Columbia: English language learning standards.

https://www2.gov.bc.ca/assets/gov/education/kindergarten-to-grade12/teach/pdfs/ell/ell-standards-full.pdf

Canadian Charter of Rights and Freedoms, s 23, Part I of the Constitution Act, 1982, being Schedule B to the Canada Act 1982 (UK), 1982, c11

Canagarajah, S., \& Said, S. B. (2011). Linguistic imperialism. In J. Simpson (Ed.), The Routledge handbook of applied linguistics (pp. 388-400). Routledge.

Common European Framework (CEFR) Ontario. (n.d.). Strategic directions for the CEFR in Ontario (2018-23). https://sites.google.com/teltgafe.com/cefr-ontario/home. 
Centre for Canadian Language Benchmarks (CCLB). (n.d.). On PBLA. https://www.language.ca/resourcesexpertise/on-pbla

Citizenship and Immigration Canada (CIC) (1996). Canadian language benchmarks: English as a second language for adults. English as a second language for literacy learners (working document). Minister of Supply and Services Canada.

Citizenship and Immigration Canada (CIC) \& Centre for Canadian Language Benchmarks (CCLB). (2002). Standards linguistiques canadiens 2002: français langue seconde pour adultes. Minister of Public Works and Services Canada.

Citizenship and Immigration Canada (CIC) \& Centre for Canadian Language Benchmarks. (CCLB). (2012a). Canadian language benchmarks: English as a second language for adults. Citizenship and Immigration Canada.

Citizenship and Immigration Canada (CIC) \& Centre for Canadian Language Benchmarks (CCLB). (2012b). Niveaux de compétence linguistique canadiens: français langue seconde pour adultes. Citizenship and Immigration Canada.

Council of Europe. (2001). A common European framework of reference for languages: Learning, teaching, assessment. Cambridge University Press.

Council of Ministers of Education, Canada (CMEC). (2010). Working with the common European framework of reference for languages (CEFR) in the Canadian context: Guide for policy-makers and curriculum designers. http://www.cmec.ca/136/Programs-and-Initiatives/Assessment/Common-EuropeanFramework-of-Reference-for-Languages-\%28CEFR\%29/index.html

Dicks, J. (2018). Aligning the Canadian language benchmarks (CLB) and the common European framework of reference (CEFR). A report prepared for the Centre for Canadian Language Benchmarks.

Dicks, J., \& Genesee, F. (2017). Bilingual education in Canada. In O. Garcia, A. M. Y. Lin, \& S. May (Eds.), Bilingual and multilingual education ( $3^{\text {rd }}$ ed., pp. 453-467). Springer.

Early, M., Dagenais, D., \& Carr, W. (2017). Second language education in Canada. In N. Van Deusen-Scholl \& S. May (Eds.), Second and foreign language education. Springer.

Figueras, N. (2007). The CEFR, a lever for the improvement of language professionals in Europe. Modern Language Journal, 91(4), 673-675.

Frost, C. (2011). How Canada killed multiculturalism. Canadian Ethnic Studies, 43(1), 253-264.

Fulcher, G. (2004a). Deluded by artifices? The common European framework and harmonization. Language Assessment Quarterly, 1(4), 253-266.

Fulcher, G. (2004b). Are Europe's tests being built on an 'unsafe' framework?: A system intended to ease comparison of language skills is failing learners, argues Glenn Fulcher. The Guardian. https://www.theguardian.com/education/2004/mar/18/tefl2

Gauthier, H. (2015). Linguistic identity and investment in grade 8 core French students (Unpublished master's thesis). Western University.

Gouvernement du Québec. (2011). L'échelle québécoise des niveaux de compétence en français pour les personnes immigrantes adultes. MICC-MELS.

Hansen, R. (2014). Assimilation by stealth: Why Canada's multicultural policy is really a repackaged integration policy. In J. Jedwab (Ed.), The Multiculturalism question: 
Debating identity in 21st century Canada (pp. 73-87). McGill-Queen's University Press.

Haque, E. (2012). Multiculturalism within a bilingual framework: Language, race, and belonging in Canada. University of Toronto Press.

Harlaux, P.-A., \& Georges, S. (2012). Rapport Canada: Le DELF DALF depuis 2005. CIEP.

Hayday, M. (2013). Canada's bilingual education revolution: The B\&B Commission and official languages in education. Canadian Issues, Fall 33, 29-33.

Heller, M. (1999). Heated language in a cold climate. In J. Blommaert (Ed.), Language ideological debates (Vol. 2, pp. 143-170). de Gruyter Mouton.

Jezak, M., \& Piccardo, E. (2017). Introduction: The Canadian language benchmarks and Niveaux de compétence linguistique canadiens - Canadian language framework in the era of glocalization. In M. Jezak (Ed.), Language is the key: The Canadian language benchmarks model (pp. 7-30). University of Ottawa Press.

Joint Advisory Committee. (1993). Principles for fair student assessment practices for education in Canada. University of Alberta. https://www.wcdsb.ca/wpcontent/uploads/sites/36/2017/03/fairstudent.pdf

Kircher, R. (2012). How pluricentric is the French language? An investigation of attitudes towards Quebec French compared to European French. Journal of French Language Studies, 22(3), 345-370.

Klinkenberg, J.-M. (2015). La langue dans la cité: Vivre et penser l'équité culturelle. Les impressions nouvelles.

Kramsch, C. (1988). The cultural discourse of foreign language textbooks. In A. J. Singerman (Ed.), Towards a new integration of language and culture (pp. 63-68). Northeast Conference on the Teaching of Foreign Languages.

Kramsch, C. (1993). Context and culture in language teaching. Oxford University Press.

Kramsch, C. (2013). Discourses of history in German language textbooks. In P. Von Münchow, C. Claudel, M. P. Ribeiro, F. Pugnière-Saavedra, \& G. Tréguer-Felten (Eds.), Cultures, discours, langues. Nouveaux abordages (pp. 145-164). LambertLucas.

Kristmanson, P., Lafargue, C., \& Culligan, K. (2011). From action to insight: A professional learning community's experiences with the European language portfolio. Canadian Journal of Applied Linguistics, 14(2), 53-67.

Kristmanson, P., Lafargue, C. \& Culligan, K. (2013). Experiences with autonomy: Learners' voices on language learning. The Canadian Modern Language Review/La revue canadienne des langues vivantes, 69(4), 462-486.

Kubota, R. (2004). Critical multiculturalism and second language education. In B. Norton \& K. Toohey (Eds.), Critical pedagogies and language learning (pp. 30-52). Cambridge University Press.

Kymlicka, W. (2008). The current state of multiculturalism in Canada and research themes on Canadian multiculturalism, 2008-2010. (Report No. 1100146482). Citizenship and Immigration Canada.

Little, D. (2007). The common European framework of reference for languages: Perspectives on the making of supranational language education policy. The Modern Language Journal, 91(4), 645-655 
Lyster, R. (2019). Translanguaging in immersion: Cognitive support or social prestige? The Canadian Modern Language Review/La Revue canadienne des langues vivantes, 75(4), 340-352.

McNamara, T. (2010). The use of language tests in the service of policy: Issues of validity. Revue française de linguistique appliquée, $X V, 7-23$

Mison, S. \& Jang, I. C. (2011). Canadian FSL teachers' assessment practices and needs: Implications for the adoption of the CEFR in a Canadian context. Synergies Europe, 6, 99-108.

Mui, T. (2015). Professional development based on the new CEFR and the new Ontario French immersion curriculum: A case study of reflective practice [Unpublished master's thesis]. Western University, London, ON.

New Brunswick Ministry of Education. (2011). Intensive French curriculum: Grade 5. https://www2.gnb.ca/content/dam/gnb/Departments/ed/pdf/K12/curric/FSL/Intensiv eFrenchGrade5.pdf

North, B. (2000). The development of a common framework scale of language proficiency. Theoretical studies in second-language acquisition. Peter Lang.

North, B. (2004, April 15). Europe's framework promotes language discussion, not directives. Education Guardian [online edition]. http://education.guardian.co.uk/tefl/story/0,5500,1191130,00.html

North, B. (2008). Levels and goals: Central frameworks and local strategies. In B. Spolsky \& F. M. Hult (Eds.), The handbook of educational linguistics (pp. 220-232). Blackwell Publishing Ltd. https://doi.org/10.1002/9780470694138.ch16

North, B. \& Piccardo, E. (2018). Aligning the Canadian language benchmarks (CLB) to the common European framework of reference (CEFR). Report commissioned by the Centre for Canadian Language Benchmarks. https://www.language.ca/aligningclb-and-cefr/

Oakes, L. \& Peled, Y. (2017). Normative language policy: Ethics, politics, principles. Cambridge University Press.

Ontario Ministry of Education. (2013). A framework for French as a second language in Ontario schools kindergarten to grade 12.

http://www.edu.gov.on.ca/eng/amenagement/frameworkFLS.pdf

Ottawa-Carleton District School Board (OCDSB), Quality Assurance Division. (2010). Grade 12 French proficiency test: Spring 2010 pilot project. Mimeo.

Ottawa-Carleton District School Board (OCDSB), Quality Assurance Division. (2011). Grade 12 French proficiency test: Results from the 2010-2011 administration. Mimeo.

Papen, R. A. (1998). French: Canadian varieties. In J. Edwards (Ed.), Language in Canada (pp. 160-176). Cambridge University Press.

Pawlikowska-Smith, G. (2000). Canadian Language Benchmarks 2000: English as a second language - Adults. Citizenship and Immigration Canada.

Phillipson, R. (1992). Linguistic imperialism. Oxford University Press.

Phillipson, R. (2010). Linguistic imperialism. In, Margie Berns (Ed.), Concise encyclopedia of applied linguistics (pp. 487-489). Elsevier.

Piccardo, E. (2013). (Re) conceptualiser l'enseignement d'une langue seconde à l'aide d'outils d'évaluations : comment les enseignants canadiens perçoivent le CECR. 
The Canadian Modern Language Review/La Revue canadienne des langues vivantes, 69(4), 386-414.

Rehner, K. (2014). French as a second language (FSL) student proficiency and confidence pilot project 2013-2014: A report of findings. https://transformingfsl.ca/wpcontent/uploads/2015/12/Student_Proficiency_Full_Report.pdf

Reitz, J. G. (2014). Multiculturalism policies and popular multiculturalism in the development of Canadian immigration. In J. Jedwab (Ed.), The Multiculturalism question: Debating identity in 21st century Canada (pp. 107-126). McGill-Queen's University Press.

Rouse, M. (n.d.). Definition. Framework. https://whatis.techtarget.com/definition/framework

Royal Commission on Bilingualism and Biculturalism. (1968). Report of the royal commission on bilingualism and biculturalism: Book II, education. Queen's Printer

Runnels, J. \& Runnels, V. (2019). Impact of the common European framework of reference - A bibliometric analysis of research from 1990-2017. CEFR Journal Research and Practice, 1, 18-32.

Saskatchewan Ministry of Education. (2013). A guide to using the common framework of reference (CFR) with learners of English as an additional language. Government of Saskatchewan. http://publications.gov.sk.ca/documents/11/82934A\%20Guide\%20to\%20Using\%20the\%20CFR\%20with\%20EAL\%20Learners.

Shohamy, E. (2001). The power of tests: A critical perspective on the uses of language tests. Longman/Pearson Education.

Soroka, S., \& Roberton, S. (2010). A literature review of public opinion research on Canadian attitudes towards multiculturalism and immigration, 2006-2009. Government of Canada. https://www.canada.ca/en/immigration-refugeescitizenship/corporate/reports-statistics/research/literature-review-public-opinionresearch-on-canadian-attitudes-towards-multiculturalism-immigration-20062009.html

Taylor, S. K. \& Cutler, C. (2016). Showcasing the translingual SL/FL classroom: Strategies, practices, and beliefs (Les classes d'accueil et d'immersion : stratégies, pratiques et croyances) [Special issue]. La Revue canadienne des langues vivantes/The Canadian Modern Language Review, 72(4), pp. 389-422.

Vandergrift, L. (2006a). New Canadian perspectives: Proposal for a common framework of reference for languages for Canada. Canadian Heritage.

http://publications.gc.ca/collections/collection_2011/pc-ch/CH4-114-2006-eng.pdf

Vandergrift, L. (2006b). Nouvelles perspectives canadiennes : proposition d'un cadre commun de référence pour les langues pour le Canada. Patrimoine canadien. http://publications.gc.ca/collections/collection_2011/pc-ch/CH4-114-2006-fra.pdf

Vandergrift, L. (2015). The DELF in Canada: Perceptions of students, teachers, and parents. The Canadian Modern Language Review/La revue canadienne des langues vivantes, $71(1), 52-74$.

Van Dijk, T. A. (2009). Context and culture. In T. A. Van Dijk (Ed.), Society and discourse: How social contexts influence text and talk (pp. 154-212). Cambridge University Press. https://doi.org/10.1017/CBO9780511575273

Weir, C. J. (2005). Limitations of the common European framework for developing comparable examinations and tests. Language Testing, 22(3), 281-300. 
Wernicke-Heinrichs, M, \& Bournot-Trites M. (2011). Introducing the CEFR in BC: Questions and challenges. Canadian Journal of Applied Linguistics, 14(2), 106128.

Yalden, M. (2013). Foreword: The B\&B Commission -50 years on. Canadian Issues, Fall 2013, 8-13.

Zumbo, B. D. (2009). Validity as contextualized and pragmatic explanation, and its implications for validation practice. In R. W. Lissitz (Ed.) The concept of validity: Revisions, new directions and applications, (pp. 65-82). IAP - Information Age Publishing, Inc.

Zumbo, B.D. (2015). Consequences, side effects and the ecology of testing: Keys to considering assessment 'In Vivo'. Plenary address, the annual meeting of the Association for Educational Assessment - Europe (AEA-Europe). https://youtu.be/0L6Lr2BzuSQ

Zumbo, B.D. (2017). Trending away from routine procedures, Towards an ecologically informed 'In Vivo' view of validation practices. Measurement: Interdisciplinary Research and Perspectives, 15(3-4), 137-139.

Zumbo, B. D. \& Hubley, A.M. (Eds.). (2017). Understanding and investigating response processes in validation research. Springer.

Zumbo, B.D., Liu, Y., Wu, A.D., Shear, B.R., Astivia, O.L.O. \& Ark, T.K. (2015). A methodology for Zumbo's third generation DIF analyses and the ecology of item responding. Language Assessment Quarterly, 12, 136-151. 


\section{Appendix \\ Links to provincial curricular documents (post-2010)}

FSL

\begin{tabular}{|c|c|}
\hline Province & Links to curricular documents \\
\hline Alberta & None \\
\hline British Columbia & $\begin{array}{l}\text { https://curriculum.gov.bc.ca/curriculum/second-languages/9/core- } \\
\text { french }\end{array}$ \\
\hline Manitoba & $\begin{array}{l}\text { Core 4-12 (2014): } \\
\text { https://www.edu.gov.mb.ca/m12/frpub/ped/fdb/cadre_4- } \\
\text { 12/docs/1_document_complet.pdf } \\
\text { Immersion K-12 (2020): } \\
\text { https://www.edu.gov.mb.ca/k12/docs/french_imm/document_orient } \\
\text { ation/full_doc.pdf }\end{array}$ \\
\hline New Brunswick & $\begin{array}{l}\text { Intensive - Grade } 5 \text { (2011): } \\
\text { https://www2.gnb.ca/content/dam/gnb/Departments/ed/pdf/K12/cur } \\
\text { ric/FSL/IntensiveFrenchGrade5.pdf } \\
\text { Post Intensive (2016) : } \\
\text { https://www2.gnb.ca/content/dam/gnb/Departments/ed/pdf/K12/cur } \\
\text { ric/FSL/PostIntensiveFrenchGrades9-12.pdf } \\
\text { Immersion 8-11e (2018): } \\
\text { https://www2.gnb.ca/content/dam/gnb/Departments/ed/pdf/K12/cur } \\
\text { ric/FSL/ProgrammeDetudes8e-11eFILA.pdf }\end{array}$ \\
\hline $\begin{array}{l}\text { Newfoundland } \\
\text { and Labrador }\end{array}$ & $\begin{array}{l}\text { Immersion (2015): } \\
\text { https://www.gov.nl.ca/eecd/files/k12_french_immersion_francais_f } \\
\text { rancais1202_october_2015_2.pdf } \\
\text { Senior High Core French }(2013) \text { : } \\
\text { https://curriculum.novascotia.ca/sites/default/files/documents/outco } \\
\text { mes-indicators- } \\
\text { files/Francais\%20arts\%20langagiers\%20tardiv\%208\%20Pilot } \% 20 a \\
\text { t\%20a\%20glance\%20\%282019\%29_2.pdf }\end{array}$ \\
\hline Nova Scotia & $\begin{array}{l}\text { Immersion } 8 \text { (2019): } \\
\text { https://curriculum.novascotia.ca/sites/default/files/documents/outco } \\
\text { mes-indicators- } \\
\text { files/Francais } \% 20 \text { arts } \% 20 \text { langagiers } \% 20 \text { tardiv } \% 208 \% 20 \mathrm{Pillot} \% 20 \mathrm{a} \\
\mathrm{t} \% 20 \mathrm{a} \% 20 \text { glance } \% 20 \% 282019 \% 29 \_2 . p d f \\
\text { Core } 8 \text { new (2019): } \\
\text { https://curriculum.novascotia.ca/sites/default/files/documents/outco } \\
\text { mes-indicators- } \\
\text { files/Francais\%20de\%20base } \% 208 \% 20 \text { pilot } \% 20 \text { at } \% 20 \mathrm{a} \% 20 \text { glance } \\
\% 20 \% 282019 \% 29 \text { 2.pdf }\end{array}$ \\
\hline
\end{tabular}


Core 10-12 (2015):

https://curriculum.novascotia.ca/sites/default/files/documents/outco mes-indicators-files/Francais\%20de\%20base \%2010-

$12 \% 20$ Outcomes\%20\%282015\%29_0.pdf

\begin{tabular}{|c|c|}
\hline Ontario & $\begin{array}{l}\text { FSL (Core, extended, immersion - 2014): } \\
\text { http://www.edu.gov.on.ca/eng/curriculum/secondary/fs1912curr201 } \\
\text { 4.pdf }\end{array}$ \\
\hline $\begin{array}{l}\text { Prince Edward } \\
\text { Island }\end{array}$ & $\begin{array}{l}\text { Core French Gr 4-6 (2016): } \\
\text { https://www.princeedwardisland.ca/sites/default/files/publications/e } \\
\text { elc_corefrench_4-6.pdf } \\
\text { Late Immersion - Gr. } 9 \text { (2016): } \\
\text { https://www.princeedwardisland.ca/sites/default/files/publications/9 } \\
\text { e_immersion_tardive_2016__0.pdf }\end{array}$ \\
\hline Québec & None \\
\hline Saskatchewan & $\begin{array}{l}\text { Core French (2012): } \\
\text { https://www.curriculum.gov.sk.ca/bbcswebdav/library/curricula/Fra } \\
\text { ncais/Francais_De_Base/MOE-44A-Core-French-8.pdf } \\
\text { French Immersion (2017): } \\
\text { https://www.curriculum.gov.sk.ca/bbcswebdav/library/curricula/Fra } \\
\text { ncais/Francais/fran\%C3\%A7ais_en_immersion_9_09may_2018.pdf }\end{array}$ \\
\hline \multicolumn{2}{|l|}{ ESL } \\
\hline Province & Links to curricular documents \\
\hline Alberta & None \\
\hline British Columbia & $\begin{array}{l}\text { ELL Policy Guidelines (2018): } \\
\text { https://www2.gov.bc.ca/assets/gov/education/administration/kinderg } \\
\text { arten-to-grade-12/english-language-learners/guidelines.pdf } \\
\text { ELL Standards (2017): } \\
\text { https:/www2.gov.bc.ca/assets/gov/education/kindergarten-to-grade- } \\
\text { 12/teach/pdfs/ell/ell-standards-full.pdf }\end{array}$ \\
\hline Manitoba & $\begin{array}{l}\text { ELL (2011): } \\
\text { https://www.edu.gov.mb.ca/k12/cur/eal/framework/section1.pdf }\end{array}$ \\
\hline
\end{tabular}


ELL Numeracy (2019): https://www.edu.gov.mb.ca/k12/cur/eal/lalnumeracy/sy/full_doc.pdf

\begin{tabular}{ll}
\hline New Brunswick & None \\
\hline $\begin{array}{l}\text { Newfoundland } \\
\text { and Labrador }\end{array}$ & $\begin{array}{l}\text { Intermediate ESL (2012): } \\
\text { https://www.gov.nl.ca/eecd/files/k12_curriculum_guides_esl_esl_int } \\
\text { ermediate_esl_for_intermediate_schoo__curriculum_guide2012.pdf }\end{array}$ \\
\hline Nova Scotia & None \\
\hline Ontario & $\begin{array}{l}\text { Anglais pour débutants 4-8 (2013) } \\
\text { http://www.edu.gov.on.ca/fre/curriculum/elementary/anglaispd48cur } \\
\text { r2013.pdf }\end{array}$ \\
\hline Prince Edward & $\begin{array}{l}\text { English 4-6 (2012): } \\
\text { https://www.princeedwardisland.ca/sites/default/files/publications/e } \\
\text { elc_english_4-6.pdf }\end{array}$ \\
\hline Québec & None \\
\hline & $\begin{array}{l}\text { A Guide to Using the Common Framework of Reference (CFR) } \\
\text { with Learners of English as an Additional Language (2013): } \\
\text { http://publications.saskatchewan.ca/api/v1/products/74054/formats/8 } \\
\text { 2934/download }\end{array}$ \\
\hline
\end{tabular}

